\title{
A Mala de Hana e a Boneca Viajante: história, narração e literatura infantil
}

\author{
Gladir da Silva Cabral
}

Eloisa da Rosa Oliveira ${ }^{* *}$

\section{Resumo}

Este artigo propóe a leitura das obras Kafka e a boneca viajante, de Jordi Sierra i Fabra (2008), e A mala de Hana: uma história real, de Karen Levine (2007), a partir de dois textos fundamentais do pensamento de Walter Benjamin (1994a, 1994b): $O$ narrador e Sobre o conceito de História. Examinamos as obras avaliando a importante função do narrador dentro delas, a concepção de história inserida em cada enredo, as questóes referentes à identidade cultural e, por fim, a representação da infância. Esta pesquisa nos levou a perceber que o exercício da narrativa ainda pode ser encontrado nos tempos atuais, seja como forma de resistência às pressóes e violências sociais, seja como recurso de reconstrução da memória e da subjetividade. Ao mesmo tempo, ficou evidente o modo como essas narrativas atuam como instrumentos de representação e construção da identidade cultural. Elas testificam que é pela linguagem, no diálogo, em sociedade, que o eu se constrói. Os dois livros também parecem confirmar a noção de que a infância produz cultura e, portanto, têm uma importante contribuiçáo a dar à sociedade e à história.

Palavras-chave: Literatura Infantil. História. Narração.

\footnotetext{
* Doutor em Letras - Inglês e Literatura Correspondente pela Universidade Federal de Santa Catarina - UFSC. Professor do curso de Letras e no Programa de Pós-Graduação em Educação da Universidade do Extremo Sul Catarinense - UNESC.

** Mestranda em Literatura da Universidade Federal de Santa Catarina - UFSC.
} 


\section{Introdução}

Karen Levine é uma escritora canadense que retrata uma história tecida em três continentes. Em A mala de Hana: uma história real (LEVINE, 2007), uma mala que chega a um pequeno museu para crianças, no Japáo, no ano 2000, desencadeia uma investigaçáo em torno dos vestígios sobre a vida de uma menina que esteve em Auschwitz em 1944. À medida que o texto biográfico vai se juntando a objetos, fotos, desenhos e depoimentos, a identidade de Hana Brady vai sendo tecida com as linhas da memória e da imaginação. A autora registra em sua obra a experiência de uma pedagoga e um grupo de crianças em Tóquio, no Japão, na organização de um museu em memória ao Holocausto. A obra perpassa também pela história de George Brady, em Toronto, no Canadá, que foi um dos sobreviventes do Holocausto e irmáo de Hana Brady, a dona da mala que está exposta no museu das crianças de Tóquio. Desse modo, a história de Karen Levine (2007) registra fatos do passado, do presente e esperanças de um futuro. Todos os envolvidos na construçáo dessa obra têm uma preocupaçáo em comum: que os horrores vividos por Hana e milhares de crianças não se repitam nem caiam no esquecimento da humanidade.

O espanhol Jordi Sierra i Fabra (2008), na obra Kafka e a boneca viajante, também fez um trabalho de investigação e imaginação. A partir da informação de que o escritor Franz Kafka, antes de sua morte, teria escrito cartas endereçadas a uma menina no parque de Steglitz, em Berlim, Sierra i Fabra (2008) decide recontar essa possível história real. Ao imaginar que conteúdos teriam essas cartas, o autor remete um olhar sobre a infância e sobre a perspectiva da morte. Todos os dias, durante algum tempo, a menina que perdeu sua boneca recebe uma carta entregue pelo carteiro de bonecas, Franz Kafka, cujo remetente é a sua própria boneca que explica todos os dias os motivos que a fizeram fugir, amenizando e libertando a menina do sentimento de perda.

Com base nessas duas obras, propomos aqui um exercício de leitura que tem como focos: o papel do narrador, o conceito de história, a identidade cultural e a representação da infância.

\section{O narrador desaparecerá?}

Walter Benjamin (1994a) sugere, numa perspectiva filosófica, que o narrador conserva fatos do passado por meio de suas narrativas, exercendo, 
assim, um diálogo entre passado, presente e futuro, pois quando o narrador conta uma história é como se estivesse deixando um legado para o presente, que para Benjamin poderá modificar o futuro. A função do narrador seria, portanto, náo só a de contar, mas principalmente a de conservar, transmitir e até salvar o significado de uma experiência como quem aconselha alguém que está disposto a ser aconselhado (BENJAMIN, 1994a).

Com base nessa perspectiva, surge ainda outra preocupação apontada por Benjamin (1994a). Em seu texto O narrador: consideraçôes sobre a obra de Nikolai Leskov (BENJAMIN, 1994a), o autor levantou a suspeita de que o verdadeiro narrador seria aquele que age em favor da troca de experiência e estaria em risco de desaparecimento diante das transformaçóes sociais e culturais da modernidade. Antônio Montenegro (2010, p. 61) comenta que, "[...] por meio de uma análise histórica rigorosa, [Walter Benjamin] lança diante de nós os perigos para a vida humana do domínio radical da modernidade". $\mathrm{O}$ desaparecimento do narrador seria, portanto, indício de uma transformação social violenta em que as narrativas tradicionais são substituídas por novos comportamentos, novas formas de narrar e novos veículos, como o romance e o jornal, "[...] aceitando a solidão do autor, assim como da personagem e do leitor, ou seja, do homem na sociedade. Perpetua-se a falsa sensação de coletividade enquanto, na verdade, ampliam-se as distâncias espaços-temporais entre os indivíduos da sociedade contemporânea" (OLIVEIRA, 2009, p. 114).

Mas por que o narrador estaria desaparecendo? Benjamin (1994a) apontou alguns fatores que teriam influenciado esse empobrecimento. Entre eles, a guerra, o retorno dos soldados que a presenciaram em sua brutalidade emudecedora, a crise da experiência, cujos indivíduos perderam o interesse pelo conselho sábio, por conseguinte a crise das tradiçôes orais em virtude do novo lugar assumido pela escrita (BENJAMIN, 1994a). Diante de todos esses fatores, um dos aspectos enfatizados que chama a atenção seria o surgimento do romance no início do período moderno, em detrimento não só da tradição oral, mas também do desejo de aconselhar. Outro fator influenciador seria o concomitante desenvolvimento da imprensa, que favoreceu o imediatismo da informação imposto pelos jornais (BENJAMIN, 1994a). Era preciso informar a sociedade, ao ponto de poupar o leitor de qualquer esforço interpretativo.

Apesar de concordarmos com Benjamin (1994a) em sua leitura quanto à crise de narrativa pela qual passa a cultura ocidental, cremos que o narrador não morreu e que o interesse pela troca de experiências, apesar de ter decaído 
e mudado de formato e mídia, também não está desaparecido, ao menos por inteiro, na sociedade contemporânea. Os livros aqui analisados evidenciam que o exercício da narração continua presente em nossos dias, ainda que de modo diferente e circunscrito a certas práticas e instituiçóes sociais, como a escola e a família, onde ainda se pode perceber a valorização da narrativa por meio da literatura infantil e juvenil. Kahmann (2006, p. 77) também faz constataçôes desse tipo em seus estudos quando afirma que:

O boom do resgate memorialístico levado a cabo, especialmente após a década de 1960, trouxe em si a necessidade de se produzir algum tipo de "verdade eterna" na qual ancorar a identidade do sujeito. Entáo, assistiu-se ao ressurgimento do narrador, com toda carga de tradiçáo oral, artesanato e aconselhamento, que queria Benjamin.

Nos dois livros aqui analisados, a ligação entre o real e o imaginário por meio de enredos adaptados para o público infantil e juvenil demonstra o interesse dos narradores em transmitir uma experiência de alguém, seja ela vivida pela personagem em questão, seja pelo próprio autor. A literatura, de fato, goza de certa liberdade ao contar a história, seja ela pela perspectiva dos vencidos, seja pela dos vencedores, pois ela trabalha com as ferramentas da ficção, da imaginação e da arte, recursos diferentes dos convencionais rigores acadêmicos, didáticos ou historiográficos, por exemplo.

$\mathrm{Na}$ literatura, pode-se mesclar a narrativa com dois ingredientes: o real e o imaginário, sem que haja compromisso com a explicação técnica mais específica da disciplina de História ou mesmo outras ciências. Realidade e imaginação estão em constante diálogo tanto na narrativa tradicional quanto na literatura, embora essa relação não seja mecânica, causal, e a literatura não seja mero espelho da realidade, mas transite entre o reflexo e a refração, como a linguagem (BAKHTIN, 1997). Entretanto, na narrativa, de acordo com Benjamin (1994a), a explicação deve ser dispensada, e o comentário deve ser mínimo a fim de gerar, instigar, proporcionar ao leitor um momento único e íntimo, que é o da interpretação. $\mathrm{O}$ romance, muitas vezes, não consegue essa síntese radical, essa contenção proposital.

Quanto ao livro Kafka e a boneca viajante (SIERRA I FABRA, 2008), por exemplo, não há provas até agora de que a menina que recebia as cartas da boneca realmente existiu, todavia tem-se certeza da existência de Kakfa, de sua 
esposa Dora Dyamant e das várias referências à menina e às supostas cartas. Sabe-se da veracidade da Praça de Steglitz, na cidade de Berlim, do banco em que supostamente Kafka se sentava com a menina. O leitor pode não ter certeza se a história contada de fato ocorreu, porém a beleza da leitura não está na certeza da veracidade daqueles fatos, mas sim na narraçáo nobre que recria uma realidade do modo como poderia ter acontecido. A narrativa habita o reino do plausível. No final do livro, Sierra i Fabra (2008) conta como surgiu a história, fornecendo dados do escritor Franz Kafka que servem de moldura histórica condizendo com os fatos fictícios narrados no livro.

Sierra i Fabra (2008) não estaria salvando uma parte desconhecida da história? Não seria esta uma narração a favor da troca de experiência? Levando em consideração o fato de que o autor estaria reconstruindo uma história que poderia ter sido esquecida, pode-se dizer que ele está cumprindo seu papel de narrador, enquanto está preocupado em recontar uma experiência possivelmente vivida por um importante escritor do século XX. Em seu texto sobre o conceito de História, fica evidente que Benjamin (1994b) concebe o olhar sobre a história dentro do contexto da redenção messiânica, que é forte no marxismo e no judaísmo, isto é, a esperança de que de alguma forma a história caminha para a sua redenção futura, para a revolução, para o estabelecimento da justiça. Ele chega a dizer, em sua terceira tese do "Conceito de História", que só a humanidade redimida pode se apropriar do passado e citá-lo (BENJAMIN, 1994b). A história de Kafka trabalha com esse aspecto remidor: a redenção da menina que sofre a perda da boneca, a redenção do próprio ofício de escritor e a redenção da narrativa.

Outro aspecto benjaminiano contemplado pela história de Sierra i Fabra (2008) é a ressignificação do passado a partir do olhar do vencido, do oprimido. No livro, o passado é construído a partir do olhar do escritor-narrador, pela imaginação, em diálogo com a criança. Partindo desse diálogo, Kafka reencontra sua própria infância: "Por que ele não encontrou um carteiro de bonecas quando era menino? Por que sempre teve que enfrentar seu pai? Por que náo havia bonecas viajantes na vida real?" (SIERRA I FABRA, 2008, p. 113). A criança sofre a perda dos vínculos com seu brinquedo, que para ela é mais que objeto, é pessoa real. Em meio à dor, consegue encontrar sinais de esperança por meio do poder consolador e surpreendente da narrativa. Mesmo que os demais adultos da praça a ignorem, a criança encontra no olhar do "carteiro de bonecas" e nas supostas cartas de Brigite a consolação, a expectativa em relação ao futuro. 


\section{Narração e identidade cultural}

Outro prisma desta análise é o tocante à identidade cultural. Nos livros selecionados para análise, percebemos que a questão da identidade está presente de forma acentuada. No livro $A$ mala de Hana, é a questâo da identidade da criança e do povo judeu. Aliás, o livro é plenamente multicultural, pois reúne infâncias do Japão, da Tchecoslováquia e adultos do Canadá. Stuart Hall (2001) discute a construçáo do conceito de identidade como processo histórico, cultural e social que se inaugura com a chegada da modernidade, mas que se desenvolve até os dias atuais. Também em Bakhtin (1997), é possível encontrar a noção de identidade como sendo socialmente elaborada a partir da noção do outro, da alteridade. A própria linguagem é fruto da interaçấo humana (BAKHTIN, 1981). Percebe-se nesses autores como a noçâo de identidade transcende aspectos subjetivistas e essencialistas. A identidade não é apenas o espaço indefinido interior das pessoas, mas fundamentalmente o das relaçóes que elas estabelecem umas com as outras.

Um dos referenciais importantes a respeito de identidade vem de Jacques Lacan (HALL, 2001), segundo o qual o olhar do outro me constrói, o que também coincide com a perspectiva bakhtiniana de alteridade. Neste caso, é a palavra do outro que constrói que dá os elementos básicos com os quais elaboro minha identidade, que em última análise é sempre resposta e pergunta à palavra do outro que me é dirigida. Em ambos os autores, fica evidente que a formação da subjetividade do indivíduo está diretamente relacionada às suas relaçôes sociais. $\mathrm{Na}$ verdade, a própria língua compreendida como fenômeno social e histórico sugere que a questáo da identidade se dá nos mesmos termos de interação e diálogo com o outro, com a comunidade onde estou inserido.

$\mathrm{Na}$ perspectiva dos Estudos Culturais, a noçáo de identidade como uma essência fixa, imutável, estável, constante, racional já não é mais possível. Também não se pode mais conceber uma identidade ancorada no biológico, no genético, no teológico ou no científico. Identidade, neste caso, é performance, relaçáo entre indivíduos e coletividade, reação à palavra e ao olhar do outro, narrativa, discurso. Tal perspectiva permite uma leitura muito interessante das obras selecionadas. A identidade do escritor em Kafka e a boneca viajante (SIERRA I FABRA, 2008), por exemplo, só é possível pelo olhar da criança e em diálogo com ela e com as demais personagens da novela, o que se aproxima 
dos conceitos benjaminianos segundo os quais o papel do narrador é dialogar com sua comunidade.

Segundo a abordagem dos Estudos Culturais, a identidade é construída por meio do discurso, da linguagem, principalmente da narrativa. Dessa forma, somos autores, narradores e personagens de uma história que nós mesmos criamos, pois a identidade é produzida pelo sujeito como forma de autoria. Ter uma identidade é autorar-se, é construir-se como herói de seu próprio enredo. Nesse sentido, Kafka é construído por Sierra i Fabra como o herói do livro, o autor das cartas (cujo conteúdo pleno não é revelado) e apresenta-se como "carteiro de bonecas", uma ficção dentro da ficção, uma personagem inventada por uma personagem num jogo de espelhos que torna o livro de Sierra i Fabra (2008) tão especial. Em A mala de Hana (LEVINE, 2007), a tessitura narrativa é particularmente complexa na medida em que apresenta um autor principal, Karen Levine, que é quem assume a narrativa, mas também conta com a participaçáo de Fumiko Ishioka, a professora japonesa que funda o Museu do Holocausto em Tóquio e reúne as crianças em torno da memória dos campos de concentração da Segunda Guerra Mundial, partindo em busca dos indícios da vida de Hana Brady. Neste caso, temos várias camadas narrativas e várias vozes. Em certo momento, ouvem-se a voz do irmão de Hana e até a da própria menina, pois seus desenhos aparecem no livro. De modo paulatino e complexo, a identidade da menina é tecida na medida em que a narrativa de sua vida é restaurada e atualizada.

Outro aspecto de imensa importância para nossa análise é a noção segundo a qual a construção das identidades se dá num contexto conflitivo, de relações de poder. Nos dois livros, há sinais de violência, guerra, depressão e sofrimento humano. No caso do livro sobre Kafka, a crise mundial trazida pela guerra e o clima de depressão parecem circundar a narrativa. Além dessa crise macro, percebe-se a situação de certo abandono pelo qual passa a infância. A menina perde sua boneca, seus vínculos afetivos, está desamparada em meio a uma sociedade indiferente ao seu sofrimento. É o olhar do escritor que a enxerga, e é ele que estabelece uma relaçáo respeitosa com a menina. Essa narrativa tem um caráter remidor na medida em que o escritor tenta salvar a infância e sua própria vocação.

É, sobretudo, na narrativa de Hana que o caráter conflitivo das construções identitárias mais se torna visível. Hana é vítima de um mundo violento e intolerante, ela é o retrato da infância condenada ao extermínio nos 
campos de concentração, condenada por sua ascendência judaica e fragilizada por sua condição de criança em meio a um mundo em guerra. Separação do irmão, lágrima, medo e morte fazem parte de um relato cheio de conflito que, de certa forma, é redimido pela narrativa da professora e da autora do livro. No livro de Hana, fica exposta a ferida do preconceito e do abandono em relação à infância. Sua voz é emudecida, sua história é que precisa ser contada agora, a contrapelo, como diria Walter Benjamin. Aliás, Benjamin (1994b) enfatiza muito bem o caráter conflitivo da cultura, o quanto há de barbárie nos monumentos culturais do mundo civilizado.

Retomando um conceito bakhtiniano (1997), podemos dizer que a construção identitária se faz pela reverberaçáo de múltiplas vozes no discurso do sujeito. O outro me habita sempre que penso ou falo, pois o outro me interpela e responde por meio da linguagem, que é objetiva, concreta, histórica. Esse concerto de vozes está presente nos dois livros analisados, mas principalmente no livro de Hana, em que o texto entrelaça as vozes de Levine, da professora, do irmão de Hana e da própria Hana, bem como de inúmeras crianças silenciadas em Terezin, Treblinka e Auschwitz. São vozes do passado, "ecos de vozes que emudeceram", como teria dito Benjamin (1994b, p. 223) na quarta tese do "Conceito de História". Esse movimento inclui a possibilidade de contradiçóes, isto é, o sujeito resultante não é uma unidade perfeita, racionalmente controlável e alinhavada, uma evolução retilínea e ascendente, mas algo incompleto, oscilante, com retrocessos.

Há que se observar, também, que o processo de construção identitária é histórico e se dá no espaço da vida real, do mundo concreto e dentro de um contexto histórico. Tal concepção coaduna-se com as perspectivas de Walter Benjamin (1994b) e de Bakhtin (1981), para quem o processo de constituição do sujeito é eminentemente histórico. Nesse processo, os bens culturais (nos termos de Benjamin) desempenham papel fundamental nesse processo. A literatura e a arte seriam, portanto, veículos importantes de construção identitária e também espaços de grande conflito cultural, social e político.

\section{As histórias dentro da História}

Por muito tempo, a história a que se teve acesso foi contada sob a perspectiva dos vencedores, pois os vencidos não sobreviveram para contála. Buscando outra perspectiva, Benjamin (1994b, p. 225) sugere que "[...] 
a história deve ser escovada a contrapelo", pois a história oficial, burguesa, filha da modernidade, já não dá mais conta de recontar o passado. É preciso ir além e encarar a dimensão remidora da história, a partir do ponto de vista dos esquecidos, por isso é necessário um olhar mais atento para que se conheçam as histórias dentro da história. Para Benjamin, na tese 12 do "Conceito de História" (1994b), o sujeito que conhece a história é o povo oprimido. No caso do livro de Hana, o aspecto remidor está na recuperação da memória da pequena Hana, vítima do regime totalitário nazista. No caso de Sierra i Fabra, é a memória da infância e o sentido da vida do escritor que estão sendo restaurados.

Encontramos um belo exemplo de história escovada a contrapelo no livro de Karen Levine (2007), A mala de Hana: uma história real. Nesse enredo, são tecidas três histórias diferentes, também nascidas da realidade, que se encontram em determinado momento e descobrem ter muito em comum. Aqui, há uma junçáo de passado, presente e futuro que perpassa um período de quase setenta anos.

A preocupação para que Auschwitz não se repita não é algo recente nem de restrita intenção de Levine (2007) e suas personagens, mas pertinente a muitos outros pensadores há certo tempo. Adorno (2003, p. 119) diz que "[...] [a] exigência que Auschwitz não se repita é a primeira de todas para a educação". Fumiko, a organizadora do projeto que inspirou a produção do livro, criou um grupo de crianças chamado "Pequenas Asas", responsáveis por disseminar a história de Auschwitz. Por meio de fotografias e desenhos da própria Hana Brady, o grupo estabeleceu contato com a história impressionante da família de Hana e com os horrores da Segunda Guerra Mundial, que também afetou tragicamente a vida do Japão. No final do livro de Levine (2007), um poema escrito pelos membros do grupo "Pequeno Asas" elucida a preocupação internalizada pelas crianças em conservar os fatos históricos dessa barbárie que, dependendo de sua vontade, nunca se repetirá:

Nós "Pequenas Asas", vamos contar a todas as crianças do Japão o que aconteceu com Hana.

Nós, "Pequenas Asas", nunca esqueceremos o que aconteceu com um milháo e meio de crianças judias.

Nós, crianças, podemos fazer a diferença em construir a paz neste mundo - para que o Holocausto nunca aconteça de novo. (LEVINE, 2007, p. 105). 
$\mathrm{Na}$ citação acima, fica evidente a perspectiva do livro de dar voz a um grupo historicamente desprezado, oprimido e violentado: as crianças. Em total consonância com o conceito benjaminiano de história analisada a contrapelo, o livro de Levine (2007) reconstrói o passado a partir do olhar da criança. Mais do que preservação da memória, o que se fez foi reconstrução da história, já que, na perspectiva benjaminiana, o passado é construído por aquele que faz a história no presente, e isso num contexto de luta e conflito, pois "[...] também os mortos não estarão em segurança se o inimigo vencer" (BENJAMIN, 1994b, p. 224-225).

Em Kafka e a boneca viajante (SIERRA I FABRA, 2008), o trabalho de investigação também ocorre, porém, diferentemente da história contada por Levine (2007), Sierra i Fabra decide dar continuidade à história de Kafka a partir de sua imaginação. $\mathrm{O}$ teor das cartas é totalmente ficcional, mas sua intenção é reconstruir uma memória do escritor Kafka. E ele também faz longa pesquisa no sentido de encontrar fatos, indícios que esclareçam e comprovem a existência das cartas e da própria menina. Diferentemente da experiência de Fumiko, Sierra i Fabra (2008) não encontra vestígios da sua menina.

A trama da boneca viajante se passa no período entre-Guerras, e o pessimismo e a preocupaçáo do que estava por vir permeavam a atmosfera de todas as vidas envolvidas naquele contexto social. Este fator relevante na vida da sociedade daquela época é influenciador também na narrativa do autor:

Virou a cabeça e olhou Dora, dormindo tranqüila a seu lado. Não eram bons tempos aqueles. A herança da Grande Guerra se fazia sentir na Alemanha. Os cinco anos transcorridos desde o fim do confronto que havia arrasado a Europa foram angustiantes, e o futuro não se mostrava muito esperançoso. (SIERRA I FABRA, 2008, p. 104).

O romance inteiro de Sierra i Fabra (2008) está circunscrito pelo contexto sombrio da Primeira Guerra Mundial recentemente terminada. Ele está em Berlim e ainda respira o clima de desesperança reinante ao redor. A Alemanha havia perdido a guerra. Entretanto, a esperança parece ser o ingrediente fundamental da história, bem em sintonia com o pensamento benjaminiano.

Longe de uma perspectiva simplesmente nostálgica em relação ao passado ou desesperada em relação ao presente, no que diz respeito ao fim do narrador, é inegável o otimismo que exala o texto de Walter Benjamin (1994b) sobre 
o conceito de História. Enquanto houver desejo, inteligência, resistência, é possível redimir o passado e ganhá-lo para o presente a partir do olhar do outro, dos excluídos, dos silenciados e sufocados. Está valendo a perspectiva benjaminiana de redenção, a esperança de que o povo oprimido, desprezado, vítima dos grandes poderes, tem em si as sementes da revolta, a possibilidade da mudança e o desejo de recriar a sociedade e a história.

\section{A infância como produtora de cultura}

A infância é outra categoria de análise importante em nossa pesquisa e elemento valiosíssimo nos dois livros selecionados. A menina desaparecida num campo de extermínio, e que, no entanto, deixa rastros de sua passagem pelos campos de concentração, e a menina que chora a boneca perdida testificam que a criança também dialoga com a cultura, tem voz e constrói sua própria subjetividade por meio da linguagem.

Apenas muito recentemente, a infância tornou-se objeto de interesse de historiadores (ARIÈS, 1981) e cientistas que lidam em muitas e diversas disciplinas: sociólogos, antropólogos, psicólogos e pedagogos. Também a literatura se preocupa com a infância e faz dela seu tema central, criando personagens, discutindo problemas concernentes à realidade das crianças ou tentando dar voz a elas, ainda consideradas por muitos como sem fala (in fans) (ZILBERMAN, 1984; BENJAMIN, 1989). Por séculos, as crianças estavam niveladas à mesma condição dos escravos e das mulheres, isto é, desprezo e abandono. Só muito recentemente é que a infância passou a ser vista como uma construção histórica (ARIÈS, 1981; SARMENTO; PINTO, 1997; SARMENTO, 2004), portanto passível de questionamento e refeitura.

Os livros aqui selecionados não foram escritos por crianças, mas para elas e sobre elas. Os livros de Sierra i Fabra (2008) e Karen Levine (2007) foram escritos tendo como alvo principal o diálogo com as crianças. Os dois reconhecem que a infância tem relevância e que a criança assimila e produz cultura. Os dois mostram como a criança não apenas tem inteligência, mas articula a linguagem de modo a ter uma voz própria. Os dois percebem que elas têm um recado a dar para a sociedade e para todos os povos: o passado náo pode ser esquecido, as crianças precisam ser ouvidas, e a sensibilidade humana precisa ser estimulada no contato com o outro. 
De acordo com Sarmento (2004), as crianças eram vistas no passado apenas como consumidoras de cultura, da qual eram aprendizes, iniciantes e aspirantes a tornarem-se futuros participantes ativos. Numa perspectiva mais romântica, a infância era vista com certa nostalgia, como um tempo de inocência e pureza primordiais. De certa forma, os livros analisados não descartam de todo certo romantismo quanto à visão da criança como contendo certa magia, certa transcendência. No entanto, os aspectos críticos e propositivos também estão presentes. A criança é vista nesses livros como produtora de cultura e participante da história, não apenas como vítima, mas como resistência e proposição. Entretanto, hoje em dia já se reconhece a criança como produtora de um tipo muito específico e diferenciado de cultura: as culturas da infância (SARMENTO, 2004).

Mais recentemente, Sarmento (2004) chama a atenção para novas condiçóes nascidas na chamada pós-modernidade que, de certa forma, modificam ou ampliam o status anterior da infância na sociedade. As crianças, como verdadeiros atores sociais, continuam a construir e propor uma identidade cultural plural e autônoma na sociedade (SARMENTO, 2004). E elas o fazem de modo estruturado, sistemático, por meio do relacionamento com seus pares e com seus relacionamentos e diálogos com os adultos, formando assim suas formas próprias de representação (SARMENTO, 2004, p. 21). Longe de ser uma tabula rasa, um espaço em branco em que suas identidades são inscritas e longe de serem seres angelicais que precisam ser protegidos a todo custo, as crianças são membros ativos da sociedade e produtores de cultura. Essa perspectiva de infância é perceptível nas obras selecionadas. Seja desenhando, seja lendo cartas, conversando com adultos ou inventando um mundo de fantasia, as crianças atuam como produtoras de cultura.

No livro de Kafka (SIERRA I FABRA, 2008), o momento decisivo chega quando a menina Elsi ouve a leitura da última carta escrita pela boneca e reage de modo positivo e determinado, dizendo-se totalmente feliz. É um momento delicado, de despedida, mas a menina reage com maturidade e autonomia. Segundo o narrador, o escritor Franz Kafka, ela falava "[...] como uma pessoa adulta, equilibrada, com tal elegância que era como se, em vez de estar no parque com ele, estivesse tomando chá com as amigas num dos cafés centrais da Potsdamer Platz. Sua mãe, Bertha, sem dúvida havia feito um bom trabalho" (SIERRA I FABRA, 2008, p. 109). É também digno de nota o impacto positivo que a menina tem sobre a vida do escritor. Há uma cena em que o escritor toma 
seus manuscritos na mão, obras importantes e de adultos como $O$ processo, $O$ castelo, $O$ desaparecido, e comenta:

Tocou as páginas. Acariciou as folhas de papel cheias de palavras corretamente escritas com sua letra bonita e miúda. Ele estava ali. De corpo e alma. O coraçấo nu de qualquer escritor. E, no entanto, de repente, a única coisa que tinha alguma lógica nas últimas semanas eram as cartas de Brígida para Elsi. Aqueles romances que nunca veriam a luz, que nunca seriam lidos, careciam de outro sentido que não fosse o testemunhal, o de sua passagem pela vida e pelo mundo. (SIERRA I FABRA, 2008, p. 103-104).

A fragilidade da infância contrasta com a violência dos tempos, segunda guerra mundial, conflito entre as naçóes, crise econômica e social. No entanto, há sinais de uma superação de traumas, sinal de autonomia e maturidade por parte da pequena Elsi. Em contraste, no livro de Hana (LEVINE, 2007), a infância é vencida pelas forças da morte e da barbárie, mas de certa forma sua memória é reconstruída a partir dos esforços de Fumiko e das crianças japonesas. Ou seja, por mais cruel e poderoso que tenha sido o regime nazista, os desenhos, fotos e recordações da pequena Hana não foram totalmente destruídos. De certa forma, o presente é redimido por meio desses pequenos fragmentos de vida e memória. Como diria Benjamin: "Quem pretende se aproximar do próprio passado soterrado deve agir como um homem que escava” (apud KRAMER, 1999, p. 246).

\section{Considerações finais}

Ao longo de nossa pesquisa, foi possível perceber que os livros trazem indícios de que o exercício da narração ainda se faz presente em nossos tempos, ainda que de forma modificada, limitada ao contexto escolar e familiar. Por meio desses livros, ainda é possível ouvir a voz do narrador advertindo e chamando para a busca da sabedoria.

Pudemos observar, também, que esses livros trazem uma concepção crítica de história ao enfatizarem a perspectiva dos esquecidos, dos silenciados, dos oprimidos. Por meio deles, é possível ouvir as vozes das crianças, dos escritores marcados pela ameaça da morte, dos vencidos, a voz do outro. 
Ao mesmo tempo, ficou evidente o modo como essas narrativas atuam como instrumentos de construção de subjetividade e identidade cultural. Elas testificam que é pela linguagem, no diálogo, em sociedade, que o eu se constrói. Por fim, percebeu-se que a criança é digna de respeito e merece ser tratada como sujeito autônomo que não apenas consome, mas produz cultura, atribui significado à realidade, lê, interpreta, entende o mundo.

\section{REFERÊNCIAS}

ARIÈS, Philippe. Historia social da criança e da família. Tradução de Dora Flaksman. 2. ed. Rio de Janeiro: Zahar, 1981.

ADORNO, Theodor W. Educação e emancipação. 3. ed. São Paulo: Paz e Terra, 2003.

BAKHTIN, Mikhail. Marxismo e filosofia da linguagem. Tradução de Michel Lahud e Yara F. Vieira. São Paulo: Hucitec, 1981.

BAKHTIN, Mikhail. A estética da criação verbal. São Paulo: Martins Fontes, 1997.

BENJAMIN, Walter. Escritos: la literatura infantil, los niños y los jóvenes. Buenos Aires: Ediciones Nueva Visión, 1989.

BENJAMIN, Walter. O narrador: consideraçôes sobre a obra de Nikolai Leskov. In: BENJAMIN, Walter. Magia e técnica, arte e politica: ensaios sobre literatura e história da cultura. São Paulo: Brasiliense, 1994a. p. 197221.

BENJAMIN, Walter. Sobre o conceito de história. In: BENJAMIN, Walter. Magia e técnica, arte e política: ensaios sobre literatura e história da cultura. São Paulo: Brasiliense, 1994b. p. 222-232.

KRAMER, Sonia. Infância, memória e saber: consideraçóes à luz da obra de Walter Benjamim. A criança e o saber, Rio de Janeiro, v. 1, p. 245-249, 1999.

LEVINE, Karen. A mala de Hana: uma história real. São Paulo: Melhoramentos, 2007. 112 p.

MONTENEGRO, Antônio Torres. História, metodologia, memória. São Paulo: Contexto, 2010. 
OLIVEIRA, Francine. A narrativa e a experiência em Walter Benjamin. In: CONGRESSO LUSOCOM: COMUNICAÇÃO, ESPAÇO GLOBAL E LUSOFONIA, 8., 2009, Lisboa. Anais... Lisboa: Universidade Lusofona, 2009. Disponível em: <http://conferencias.ulusofona.pt/index.php/ lusocom/8lusocom09/paper/viewFile/61/37>. Acesso em: nov. 2011.

SIERRA I FABRA, Jordi. Kafka e a boneca viajante. São Paulo: Martins, 2008. 127 p.

SARMENTO, Manuel Jacinto. As culturas da infância nas encruzilhadas da Segunda Modernidade. In: SARMENTO, Manuel Jacinto; CERISARA, Ana Beatriz. Crianças e miúdos: perspectivas sociopedagógicas da infância e Educação. Lisboa: Asa Editores, 2004.

SARMENTO, Manuel Jacinto; PINTO, Manuel. As crianças e a infância: definindo conceitos, delimitando o campo. In: PINTO, Manuel; SARMENTO, Manuel Jacinto. As crianças, contextos e identidades. Braga: Universidade do Minho, 1997.

KAHMANN, Andrea Cristiane. Fronteira, identidade, narrativa: tradição e tradução em Sergio Faraco. 2006. 193 f. Dissertação (Mestrado em Literatura Comparada) - Universidade Federal do Rio Grande do Sul, Porto Alegre, 2006.

ZILBERMAN, Regina. Literatura infantil: autoritarismo e emancipação. 2. ed. São Paulo: Ática, 1984. 


\section{La maleta de hana y la muñeca viajera: narrativa historia, literatura y niños}

\section{Resumen}

Este artículo propone una lectura de la obra Kafka y la muñeca viajera, de Jordi Sierra i Fabra (2008), y La maleta de Hana: un relato verídico, de Karen Levine (2007), basado en dos textos fundamentales de Walter Benjamin (1994a, 1994b): "El narrador" y "Sobre el concepto de la Historia". Este texto examinaron el papel importante del narrador, la concepción de la historia, las cuestiones de identidad cultural y la representación de la infancia en las obras seleccionadas. Esta investigación nos ha llevado a comprender que el ejercicio de la narrativa todavía se puede encontrar en los tiempos modernos, tanto como una forma de resistencia a las presiones sociales y la violencia, como también un recurso reconstrucción de la memoria y la subjetividad. Al mismo tiempo, se hizo evidente cómo estos relatos actúan como instrumentos de representación y construcción de la identidad cultural. Ellos testifican que el individuo se construye través el lenguaje, el diálogo en la sociedad. Ambos libros también parecen confirmar la idea de que la infancia produce cultura y por lo tanto tienen una importante contribución que hacer a la sociedad y la historia.

Palabras claves: Literatura infantil y juvenil. Historia. Narración.
Hannah's suitcase and the traveling doll: history, narrative and children's literature

\section{Abstract}

Considering the ideas from two fundamental texts by Walter Benjamin, "The Narrator" and "On the Concept of History," we propose a reading of Kafka e a Boneca Viajante, by Jordi Sierra e Fabra, and A Mala de Hana: uma história real, by Karen Levine. In each book we evaluate the importance of the function of the narrator, the concept of history, the issue of cultural identity and the representation of childhood. We observed that the exercise of narrative can still be found as a way to resist social oppression and violence and as a strategy to reconstruct memory and subjectivity. At the same time, it was clear how these narratives function as instruments of representation and elaboration of cultural identity. The two books also appear to confirm the concept that children produce culture and, therefore, make an important contribution to the understanding of society and history. Keywords: Children's literature. History. Narrative. 
Gladir da Silva Cabral

E-mail: gla@unesc.net

\section{Eloisa da Rosa Oliveira}

E-mail: eloisa_oliveira88@hotmail.com

Recebido em: 22/2/2012

Versão final recebida em: 4/12/2012

Aprovado em: 17/12/2012 